This item was submitted to Loughborough's Research Repository by the author.

Items in Figshare are protected by copyright, with all rights reserved, unless otherwise indicated.

\title{
Multi-objective optimal control of small-size wastewater treatment plants
}

PLEASE CITE THE PUBLISHED VERSION

http://dx.doi.org/10.1016/j.cherd.2015.06.039

\section{PUBLISHER}

(c) Elsevier

VERSION

AM (Accepted Manuscript)

\section{PUBLISHER STATEMENT}

This work is made available according to the conditions of the Creative Commons Attribution-NonCommercialNoDerivatives 4.0 International (CC BY-NC-ND 4.0) licence. Full details of this licence are available at: https://creativecommons.org/licenses/by-nc-nd/4.0/

\section{LICENCE}

CC BY-NC-ND 4.0

\section{REPOSITORY RECORD}

Rainier, Hreiz, Nicolas Roche, Brahim Benyahia, and M.A. Latifi. 2015. "Multi-objective Optimal Control of Small-size Wastewater Treatment Plants". figshare. https://hdl.handle.net/2134/18573. 


\title{
Multi-objective optimal control of small-size wastewater treatment plants
}

\author{
Rainier Hreiz ${ }^{\mathrm{a}, \mathrm{b}, *}$, Nicolas Roche ${ }^{\mathrm{b}}$, Brahim Benyahia ${ }^{\mathrm{c}}$, M.A. Latifi ${ }^{\mathrm{a}}$
}

\begin{abstract}
In this work, a multi-objective dynamic optimization of the operating strategy of a small-size wastewater treatment plant is carried out. In-situ incineration of the excess sludge produced for electricity production is investigated in order to reduce the operating costs. The trade-offs between the treatment quality and the operating costs are characterized. Compared to the literature, emphasis is put on a more rigorous formulation of the problem and an accurate modeling of the underlying phenomena so as to get physically relevant solutions. Thus, from a mathematical perspective, the problem is formulated so that the solution is less sensitive to the - arbitrarily chosen - plant initial conditions. Modeling of physical phenomena e.g. the detrimental effect of the concentration of suspended solids in the mixed liquor, on oxygen transfer rate, has been included in the model. Several constraints are added to the problem so as to maintain the optimal solutions within the limits of validity of the mathematical model. The results provided a clear picture about the trade-offs between the treatment quality and the exploitation costs. Sludge incineration was shown to be of a high energetic profit, but it does not allow the plant to be electrically autonomous.
\end{abstract}

Keywords: Wastewater treatment, Activated sludge, Dynamic optimization, Multi-objective optimization, Pareto front

\section{Introduction}

The activated sludge process, ASP (Figure 1), is nowadays the most widely used process for municipal wastewater treatment. The infrastructure of the basic ASP consists of: (1) an aerated bio-reactor operated continuously where suspended microorganisms mineralize the incoming colloidal and dissolved organic pollution. (2) a settling tank where activated sludge (flocculated biomass) is gravitationally separated from the treated wastewater. The treated effluent overflows into the receiving waterbody, or in some wastewater treatment plants (WWTPs), is directed toward a tertiary treatment stage where it undergoes additional treatments. (3) a sludge recycle line returning the major proportion of the settled sludge to the bio-reactor. Hence, a high bacterial concentration can be maintained in the reactor so as to intensify the biological pollutant removal. A primary benefit of sludge separation and recycling is the decoupling of the hydraulic and solids retention times (HRT and SRT respectively. SRT is often referred to as "sludge age"). In fact, while HRT is of the order of ten hours, a minimum SRT of 3 days is required for bacteria to aggregate into flocs so as to enable their gravitational separation. (4) a sludge wastage line where excess sludge originating from the continuously growing biomass is purged and then treated separately.

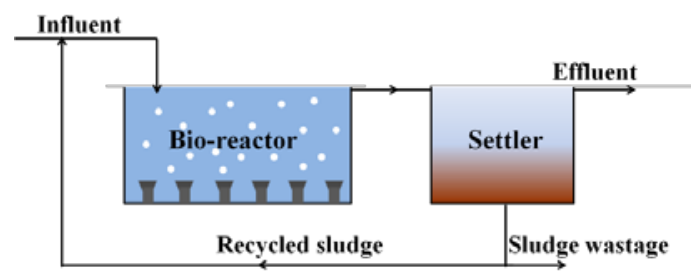

Figure 1: Schematic diagram of the basic activated sludge process.

The basic ASP allows an efficient removal of carbonaceous organics and ammonium/ammonia $\left(S_{\mathrm{NH}}\right)$ from the wastewater. To enhance nitrogen removal, most small-size WWTPs have adopted the alternating activated sludge (AAS) version of the ASP. It consists in sequentially aerating the bio-reactor to provide alternating aerobic (supplies dissolved oxygen, DO, to bacteria) and anoxic conditions (depletion of DO but presence of nitrate/nitrite, $\mathrm{S}_{\mathrm{NO}}$ ). Under aerobic metabolism, ammonium is nitrified into $\mathrm{S}_{\mathrm{NO}}$ (nitrification process). The aeration-off periods enable minimizing the electrical consumption, and by depriving bacteria from DO, force them to use $\mathrm{S}_{\mathrm{NO}}$ as a substitute terminal electron acceptor and to reduce it into nitrogen gas (denitrifcation process).

\footnotetext{
${ }^{a}$ Laboratoire Réactions et Génie des Procédés, CNRS-ENSIC, Université de Lorraine, BP-20451, 1 rue Grandville, 54001 Nancy Cedex, France.

${ }^{\mathrm{b}}$ Aix-Marseille University - CNRS - Centrale Marseille, Laboratoire de Mécanique, Modélisation et Procédés Propres - UMR7340, Europôle de l’Arbois, 13545 Aix en Provence Cedex 4, France.

${ }^{c}$ Department of Chemical Engineering, Loughborough University, Loughborough, Leicestershire LE11 3TU, United Kingdom.

* Corresponding author at: Rainier Hreiz, Laboratoire Réactions et Génie des Procédés, CNRS-ENSIC, Université de Lorraine, 1 rue Grandville, 54001 Nancy Cedex, France. Tel : +33 (0) 383175 179. E-mail address: Hreiz.Rainier@gmail.com ; Rainier.Hreiz@univlorraine.fr
} 
Nowadays, since complying with the continuously strengthening environmental regulations involves additional costs, the wastewater industry is forced to improve the ASP functioning. In this context, dynamic optimization reveals to be a powerful tool for assisting and supporting designers in determining the optimal operating conditions for existing WWTPs, or simultaneously predicting the optimal design and operation for future plants. Numerous studies dealing with the single objective optimization (SOO) of ASPs' functioning have been published in the last decade. Chachuat et al. (2001, 2005a, 2005b), Fikar et al. (2005) and Balku and Berber (2006) focused on the optimization of AAS operation. They determined the aeration sequences minimizing the aerators' energy consumption while satisfying the effluent constraints. Kim et al. (2000) applied Real-Time Optimization to a laboratory-scale AAS. Their experimental measurements confirmed that high COD (chemical oxygen demand) and nitrogen removal efficiencies were achieved. Coelho et al. (2000) and Souza et al. (2008) considered minimizing the batch time of a sequencing batch reactor, i.e. maximizing its productivity. Guerrero et al. (2011) addressed the optimization of a large-size WWTP. They determined the setpoints values of the control system that minimize the process's exploitation costs. Descoins et al. (2012) investigated the electrical autonomy of a large-size WWTP where sludge is stabilized in an anaerobic digester, and the produced biogas is burned for electricity production. Their results revealed that, unless the effluent limits are very strict, the WWTP can attain the electrical autonomy, and even produce important surplus of electricity.

Some papers have also addressed the optimal design of future ASPs, i.e. determining the optimal units' sizing and process's operation minimizing the total plant cost (i.e. construction and exploitation charges). EspíritoSanto et al. (2006, 2007) considered the optimal design and operation of the basic ASP. Rivas et al. (2008) focused on the so called Alpha process. They considered minimizing the total reactors' volume, which thus reduces the plant's construction costs. However, proceeding so, they did not account for exploitation charges which can constitute up to 50\% of the total ASP's cost (Espírito-Santo et al., 2006). Rigopoulos and Linke (2002) and Alasino et al. $(2007,2010)$ addressed the optimal design and operation of large WWTPs on the basis of a superstructure formulation, i.e. a general flowsheet embedding numerous interesting process's layouts.

Recently, in the framework of the optimal control/design of WWTPs, there is an increasing attention to multiple-objective optimization (MOO). Indeed, as most real-world processes, ASPs require the simultaneous optimization of several objectives, e.g. minimizing the exploitation costs and maximizing the treatment efficiency. Contrary to SOO, MOO is able to account comprehensively for such different criteria, and thus provides the designer with information about the trade-offs involved between the different objectives that he/she would like to optimize. However, since conflicting criteria are tackled together in MOO, there is no unique solution that can simultaneously optimize all the objectives set. Therefore, the notion of optimality is redefined and the 'Pareto dominance' concept is used to compare solutions: a feasible solution dominates another one only if it leads to a superior or equal performance with respect to all the evaluation criteria. Thus, a solution is said to be - Pareto - optimal if it is not dominated by any other feasible solution. Thus, MOO leads to a set of optimal solutions known as the Pareto front, PF. If we consider for example the case where the treatment's quality and cost are optimized, the PF represents the minimal cost enabling a given treatment efficiency.

Several recent studies, e.g. Costa et al. (2011) and Egea and Gracia (2012), have used MOO to investigate the trade-offs between the treatment costs and the achieved effluent quality in ASPs. Guerrero et al. (2012) considered an additional objective function in their optimization problem, the minimization of the risk of microbiology-related solids separation problems (bulking, foaming or rising sludge). Hakanen et al. (2011, 2013) used an interactive MOO approach to select the most preferred operating strategy of a large-size WWTP. For more details about the optimal control and design of ASPs, the reader may consult the literature review by Hreiz et al. (2015) that addresses both SOO and MOO cases.

The present paper deals with the multi-objective optimal control of a small-size WWTP for carbonaceous and nitrogenous pollution removal. In-situ incineration of the excess sludge produced for electricity production is investigated as a promising option to reduce the exploitation costs. A rigorous optimization framework is proposed so as to get physically relevant results. Discharge constraints are accounted for only after a time delay to avoid that the plant initial state influences the optimal solutions. Sludge age, i.e. SRT, is constrained between 4 and 30 days to guarantee good sludge settleability and limit sludge mineralization since it alters its calorific value. The effects of the mixed liquor characteristics on the oxygen mass transfer rate are considered. Constraints are applied to the dissolved oxygen concentration in the reactor to guarantee that the optimal solutions remain within the limits of validity of the mathematical model.

\section{Multi-objective optimization problem statement}

\subsection{Process configuration}

The investigated ASP consists of a single reactor $\left(V=6,000 \mathrm{~m}^{3}\right)$ operating continuously and equipped with a diffused aeration system, and of a cylindrical settler (height $=4 \mathrm{~m}$, cross-section $=1,500 \mathrm{~m}^{2}$ ). The injected air 
flow rate can be controlled by means of valves installed on the air lines. During non-aeration periods, a submersible mixer maintains the solids in suspension. The produced sludge is valorized in an in-site incineration engine to produce electricity. Influent characteristics (flow rate, composition) are time-varying, and reflect typical disturbance resulting from the life patterns of households (dry-weather file by Copp (2002)). The average incoming flow rate is about $18,000 \mathrm{~m}^{3}$.day ${ }^{-1}$, thus the mean HRT in the reactor is nearly 8 hours.

It should be noted that several studies dealing with the optimal control of ASPs have considered a steady influent (Descoins et al. (2012) among others). Indeed, in such a case, if the ASP operation is also steady, the problem can be formulated as a static optimization problem, which simplifies the calculations. However, as shown by Rivas et al. (2008), designs based on time-varying influent characteristics are more conservative than those obtained assuming a steady influent. Therefore, in this study, a dynamic influent is considered so as to obtain realistic solutions, especially that the temporal variations of the influent characteristics constitute the main source of disturbance to the ASP's operation.

\subsection{Process model}

The bio-reactor is treated as an ideal continuous stirred-tank reactor, CSTR. The occurring biochemical reactions are modelled using the well-known ASM1 model (Henze et al., 1987). ASM models, developed by the International Water Association, are nowadays established as standards by the scientific community since they produce good predictive results by simulation. ASM1 tracks the temporal evolution of 13 key state variables of the ASP, such as the concentrations of DO, heterotrophic and autotrophic bacteria, soluble and particulate nitrogen and carbonaceous substrates. Mass balances around the reactor for each of these variables give rise to 13 highly non-linear ordinary differential equations (ODEs). ASM1 models the conversion processes of each variable, which represent source and sink terms in the dynamic mass balance equations. In the case of the biomass for example, these terms correspond to the bacterial growth and death respectively.

The settling tank is treated as a non-reactive unit. Liquid-solid separation is modelled according to the wellknown Takács et al. (1991) model, which is nowadays the most accepted dynamic model for the clarificationthickening processes occurring in the secondary clarifier. It assumes a $1 \mathrm{D}$ settler consisting of 10 CSTR layers. Mass balances of the state variables are performed around each layer and lead to 80 ODEs. Sludge's settling velocity is assumed to depend only on the local concentration of total suspended solids, TSS (Kynch theory). It is calculated through a double exponential function, a formulation that accounts for both hindered and flocculated settling. Clarification is considered above the feed layer, and thickening below the inlet level and in the sludge blanket. In layers where thickening occurs, the solids' sedimentation flux is limited to that which can be handled by the layer below (limiting flux concept).

For details about the coupling between ASM1 and the model of Takács et al. (1991), the reader may refer to the works of Copp (2002) and Alex et al. (2008).

\subsection{Optimization problem formulation}

The MOO problem can be stated as follows:

$$
\operatorname{Min}_{\boldsymbol{u}} \boldsymbol{J}\left(\boldsymbol{x}, \boldsymbol{u}, t_{f}\right)=[\text { Operating costs, Nitrogen discharge }]^{\mathrm{T}}
$$

Subject to:

$$
\begin{aligned}
& \text { Process model equations: } \boldsymbol{f}(\boldsymbol{x}, \dot{\boldsymbol{x}}, \boldsymbol{u}, t)=\mathbf{0} \\
& \text { Initial conditions: } \boldsymbol{x}\left(t_{0}\right)=\boldsymbol{x}_{0} \\
& \text { Constraints: } \boldsymbol{g}(\boldsymbol{x}, \boldsymbol{u}) \leq \mathbf{0} \\
& \text { Decision variables bounds: } \boldsymbol{u}_{L} \leq \boldsymbol{u} \leq \boldsymbol{u}_{U} \\
& \quad \text { with } \boldsymbol{u}=\left[Q_{A i r}(t), Q_{w}(t), Q_{R}\right]^{\mathrm{T}}
\end{aligned}
$$

where $t$ is the time and $t_{f}$ the time horizon; $\boldsymbol{x}$ represents the set of the 13 process state variables (and $\dot{\boldsymbol{x}}$ its time derivative); $\boldsymbol{u}$ is the set of decision variables (DVs): $Q_{\text {Air }}$ the injected air flow rate, $Q_{w}$ the sludge wastage flow rate and $Q_{R}$ the external recycling flow rate. The superscript T stands for the transpose; $\boldsymbol{u}_{L}$ and $\boldsymbol{u}_{U}$ are the DVs' lower and upper bounds respectively; $\boldsymbol{g}$ represents the set of inequality constraints that must be fulfilled by the optimal solution.

$Q_{\text {Air }}$ and $Q_{w}$ are considered as time-varying DVs. The situation can be achieved physically thanks to valves installed on the air and sludge lines. Time-varying aeration rate is necessary to allow performing nitrification and denitrification in the same tank, and is also beneficial to better handle large load variations. For example, aeration can be increased under high loads to handle the incoming pollution, and decreased during low loads to save energy. Considering $Q_{w}$ as a time-varying DV allows the optimizer to adjust the TSS concentration in the reactor to avoid the settler's overload under peakflows for example. $Q_{A i r}$ and $Q_{w}$ are parameterized using the sequential CVP (Control Vector Parameterization) approach: the time horizon is divided into several intervals of 
equal length (2, 4 or 24 hours, see Section 3), and the DVs are approximated using piece-wise constant functions over each interval. $Q_{R}$ is treated as a time-independent DV: in practice, the recycle flow is lifted by a screw pump which is generally operated at constant capacity.

The MOO problem seeks for the optimal daily operating strategies and considers a time horizon of 100 days (i.e. the same daily operating policy is repeated during these 100 days). Such a large time frame is required so as to get solutions guaranteeing a sustainable plant operation. In fact, as shown by Chachuat et al. (2005a), operating procedures determined from a short time operation optimization can lead to biomass washout, and thus, to catastrophic plant performance on the long term. The operating costs objective function involves pumping, aeration and mixing power consumptions. The excess sludge produced is valorized through incineration to produce electricity which reduces exploitation costs (cost functions are reported in Section 2.4). The treatment quality objective function is mathematically stated as the minimization of the effluent average total nitrogen concentration between the $86^{\text {th }}$ and the $100^{\text {th }}$ day. Such a formulation (Copp, 2002) ensures that the objective function is computed during the cyclic steady regime only, and hence mitigates the effects of the initial plant state with regard to the computed PF. In fact, the initial conditions should not influence the optimal solution since their effects vanish with time.

The problem is solved using an elitist multi-objective genetic algorithm whose details can be found in (Benyahia et al., 2011; Benyahia, 2009). Since they are a population-based metaheuristic, genetic algorithms are well adapted for handling MOO problems, and contrary to most scalarization techniques, they are not - or little susceptible to the shape and convexity of the PF. For all investigated cases, a population of 400 individuals is used and the algorithm stops after 35 generations.

\subsection{Cost functions}

\subsubsection{Aeration costs}

$Q_{\text {Air }}$ and the oxygen mass transfer coefficient $\left(k_{L} a\right)$ are linked through the empirical formula derived by Gillot and Héduit (2004) from on site measurements in ASPs:

$$
k_{L} a=1.477 h^{-0.136} S^{-1.175} S_{p}^{0.042} S_{a}^{0.145} Q_{\text {Air }}^{1.037}
$$

where $h$ is the water column height in m (taken as $4 \mathrm{~m}$ in the present study), $S_{a}$ the surface covered by the diffusor modules in $\mathrm{m}^{2}$ (considered equal to the surface of the reactor), $S_{p}$ the total membrane surface in $\mathrm{m}^{2}$ (taken as $7 \%$ of the reactor surface), $k_{L} a$ is in $\mathrm{h}^{-1}$ and $Q_{\text {Air }}$ in $\mathrm{Nm}^{3} \cdot \mathrm{h}^{-1}$. This formula has been derived from measurements in aerobic reactors, and therefore, is valid for important aeration rates only. However, our preliminary results suggested the incorporation of additional constraints on DO limits. Using these supplementary constraints (see Section 3.1), Equation 6 is expected to provide realistic results over the feasible solutions space.

The mixed liquor is far more complex than a pure air-water system since it generally contains many species having an important impact on $k_{L} a$ (Painmanakul and Hébrard, 2008). Moreover, it exhibits very complex nonNewtonian behaviors depending on its TSS content, the wastewater strength and type and the bio-reactors' performance (Seyssiecq et al., 2003). The mixed liquor viscosity significantly influences $k_{L} a$ since it impacts the DO convective transport. All the effects of this complex environment on the mass transfer rate are gathered together into an $\alpha$ factor, generally lower than one in the case of wastewater and mixed liquor, and that is expressed as:

$$
\alpha=\frac{k_{L} a_{\text {Mixed Liquor }}}{k_{L} a_{\text {Pure Water }}}
$$

Thus, to account for the effects of the mixed liquor characteristics on the mass transfer rate, Equation 6 should be corrected using the $\alpha$ factor. In the present study, $\alpha$ is supposed to depend mainly on the TSS concentration in the mixed liquor, and the corrective formula is deduced from the experimental results of Marrot et al. (2005) (valid for 0 g. $\left.\mathrm{L}^{-1} \leq \mathrm{TSS} \leq 10 \mathrm{~g} . \mathrm{L}^{-1}\right)$ :

$$
\alpha=-0.072 \times T S S+1
$$

Note that according to the measurements of Marrot et al. (2005), $\alpha$ is independent of the air flow rate. TSS concentration in ASPs typically lies in the range 3-5 g. $\mathrm{L}^{-1}$. Assuming that the mean TSS concentration in the reactors investigated by Gillot and Héduit (2004) was 4 g.L ${ }^{-1}$ (a concentration to which corresponds an $\alpha$ value of 0.712.), $k_{L} a$ is therefore calculated in the present study according to:

$$
k_{L} a=1.477 h^{-0.136} S^{-1.175} S_{p}^{0.042} S_{a}^{0.145} Q_{\text {Air }}^{1.037} \frac{\alpha}{0.712}
$$

Finally, the electrical power consumed by the blower is calculated assuming an adiabatic compression (Gillot et al., 1999) and a constant blower efficiency of $70 \%$. 
To the authors' knowledge, accounting for the reduction of the mass transfer rate - due to the non-Newtonian properties of the activated sludge - is novel in the framework of the optimization of ASPs' operation/design. Taking this effect into consideration leads to more realistic results, especially that it significantly affects the optimal solutions as shown later.

\subsubsection{Other costs}

Pumping power consumption includes many contributions: influent pumping, flow recycling and sludge wastage. However, the influent pumping cost does not depend on the operating strategy since it is dictated by the incoming wastewater flow rate. Therefore, it has not been included in the exploitation costs objective function. Sludge wastage is supposed to be gravity-driven in the investigated WWTP and therefore does not require any pumping. Recycling pumping power is calculated according to the formula:

$$
\text { Pumping power }=\frac{\rho g Q_{R} \Delta H}{\eta_{P}}
$$

where $\rho$ is the pumped fluid density, $g$ the gravitational acceleration, $\Delta H$ the differential head and $\eta_{P}$ the pump efficiency. Since TSS concentration varies in a narrow range only, $\rho$ remains practically constant and equal to $1,000 \mathrm{~kg} \cdot \mathrm{m}^{-3} . \Delta H$ and $\eta_{P}$ are difficult to calculate especially that they depend on the pumped flow rate. For simplification purposes, they are supposed constant and equal to $4 \mathrm{mWC}$ and $50 \%$ respectively.

AS reactors must be mechanically stirred to achieve homogenization, and most importantly, to maintain the activated sludge in suspension and in contact with the wastewater. Otherwise, the sludge would settle which reduces the reactors' capacity and could even lead to undesired anaerobic zones. The electrical consumption of the submersible mixer is modeled according to the formulation of Alex et al. (2008): the mixer is used only when the achivied $k_{L} a$ is lower than $20 \mathrm{~h}^{-1}$, and its specific power consumption is $5 \mathrm{~W} . \mathrm{m}^{-3}$. Indeed, under sufficient aeration conditions, the flow induced by the bubbles injection is supposed to satisfy the mixing requirements.

The extracted sludge is thickened, dewatered and dried so it can burn. These operations are supposed to cost $1 \mathrm{kWh}$ per kg of dry sludge. Sludge is then valorized in an in-site incineration engine (30\% efficiency) for electricity production. Its calorific value is supposed constant and equal to $15 \mathrm{MJ}$ per kg of dry sludge.

\subsection{Constraints and decision variables bounds}

Effluent limits for COD, $\mathrm{BOD}_{5}$ (five-day biological oxygen demand) and TSS are handled through inequality path constraints: their instantaneous concentrations must remain below the specified limits of 100, 10 and 30 g. $\mathrm{m}^{-3}$ respectively. Compared to the literature, a more correct formulation is provided (Equations 11, 12 and 13): these constraints are accounted for only between the $86^{\text {th }}$ and the $100^{\text {th }}$ day. Such a large time delay ensures that the cyclic steady state is reached. Indeed, activating a constraint during the transient period makes the numerical solution depending on the arbitrarily guessed plant's initial state (whose effects should vanish with time).

$$
\begin{aligned}
& \text { If } 86 \text { days } \leq t \leq 100 \text { days: } \\
& \qquad \operatorname{COD}^{\text {Effluent }}(t) \leq 100 \mathrm{~g} \cdot \mathrm{m}^{-3} \\
& \operatorname{BOD}_{5}{ }^{\text {Effluent }}(t) \leq 10 \mathrm{~g} \cdot \mathrm{m}^{-3} \\
& \operatorname{TSS}^{\text {Effluent }}(t) \leq 30 \mathrm{~g} \cdot \mathrm{m}^{-3}
\end{aligned}
$$

For an efficient gravity settling in the clarifier, bacteria must be flocculated, i.e. aggregated into enough large units. The bio-flocculation is partly due to the production of extra-cellular polymers which fix the bacteria together. In ASP, microbes require a minimum sludge age (i.e. SRT) of about 3-4 days to develop a sticky slime layer. On the other hand, too large SRTs lead to poorly settleable flocs, and this for different reasons among which the overgrowth of filamentous bacteria. Therefore, in the present work, the sludge age is restricted between 4 and 30 days. In addition to guaranteeing good floc settleability, the most important purpose of the upper bound is to limit the sludge mineralization since it alters the sludge calorific value. Indeed, a constant calorific value of the sludge (i.e. independent of its content in organic matter) of $15 \mathrm{MJ}$ per $\mathrm{kg}$ is assumed as stated previously.

The screw pump is supposed to provide a maximum flow rate $Q_{R}$ of $40,000 \mathrm{~m}^{3}$.day ${ }^{-1}$. The maximum value of $Q_{w}$ is set to $1,000 \mathrm{~m}^{3}$.day ${ }^{-1}$. According to Grady et al. (1999) (cited by El-Shorbagy et al. (2011)), to prevent bioflocs shearing, $Q_{\text {Air }}$ should not exceed:

$$
\frac{1000 Q_{\text {air }}}{\operatorname{Lim}} \leq V
$$


where $\operatorname{Lim}$ equals $90 \mathrm{~m}^{3} /\left(\min .1000 \mathrm{~m}^{3}\right)$ and $V$ represents the reactor's volume. However, in the present study, a value of $\operatorname{Lim}$ of $50 \mathrm{~m}^{3} /\left(\min .1000 \mathrm{~m}^{3}\right)$ is assumed so that the maximum $Q_{\text {air }}$ matches the capacity of aerators typically used nowadays.

\section{Results and discussion}

The MOO problem is solved for 3 situations. In the $1^{\text {st }}$ problem, $Q_{\text {Air }}$ and $Q_{w}$ are allowed to change values every 2 hours (i.e. 12 cycles by day), which results in 25 DVs. The $2^{\text {nd }}$ problem is similar, but sludge disposal and valorization are not accounted for in the exploitation costs objective function. In the $3^{\text {rd }}$ problem, $Q_{A i r}$ and $Q_{w}$ are taken as time-independent DVs (thus the problem involves 3 DVs only) so as to characterize the benefits provided by dynamic operating conditions (sludge-related charges are taken into consideration). The PFs corresponding to the first two problems are shown in Figure 2. Each one required about 6 days of CPU time on a $3.1 \mathrm{GHz}$ personal computer (while the PF of the $3^{\text {rd }}$ problem necessitated about 2 days).

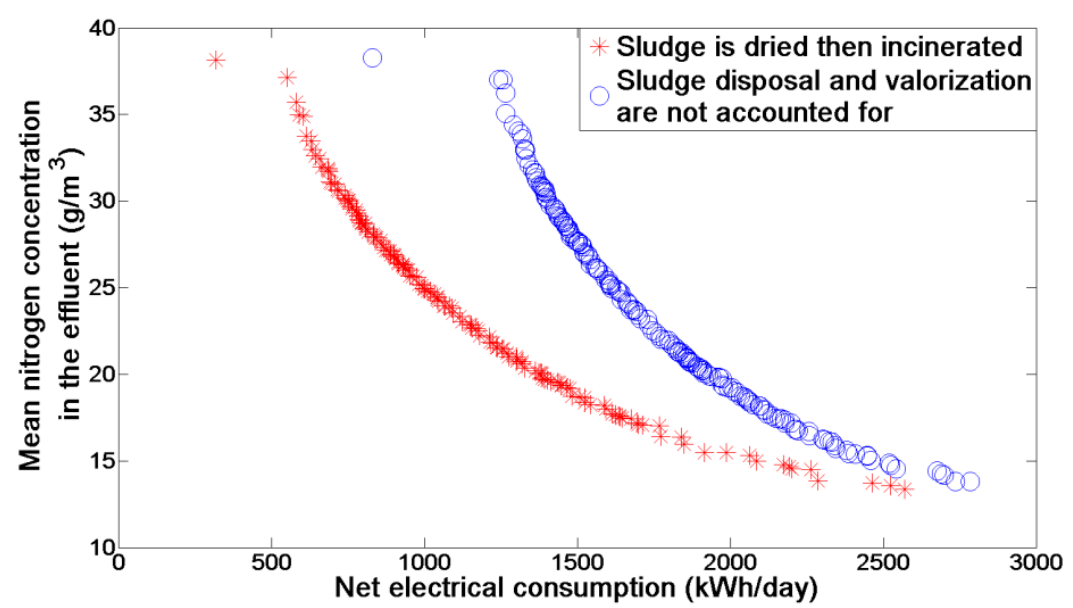

Figure 2: Pareto fronts when sludge disposal and valorization are respectively accounted and not accounted for in the exploitation costs objective function.

The results show that the treatment operating costs increase with increased efficiency of nitrogen removal. Comparing the 2 PFs shows that sludge incineration is more profit-making when high nitrogen discharge limits are tolerated. However, this does not mean that sludge production decreases with tightening effluent limits. Indeed, the optimal policies are not the same for the 2 problems.

When the $3^{\text {rd }}$ problem was solved, the resulting PF (not shown here) was found to be nearly the same as for the $1^{\text {st }}$ problem. At first sight, this outcome is quite surprising since a constant $Q_{\text {Air }}$ does not allow performing both nitrification and denitrification. A closer look to the results revealed that for the 3 problems, the optimal solutions correspond to conditions of low DO in the reactor, about 0.2-0.4 g.m $\mathrm{m}^{-3}$. In fact, in the framework of ASM1, such conditions allow simultaneous nitrification and denitrification at low aeration costs, i.e. an excellent treatment with low operating charges. Although the results are mathematically correct, they are physically irrelevant since in practice, ASPs cannot achieve an efficient treatment in this range of DO concentrations. In fact, as discussed by Rigopoulos and Linke (2002), the accuracy of ASM1 in this range of DO conditions is questionable.

\subsection{Additional constraints relative to the DO concentration}

Espírito-Santo et al. (2006, 2007) constrained the DO concentration in their classic ASP to be above 2 g.m $\mathrm{m}^{-3}$. Likewise, Balku and Berber (2006) imposed to the average DO concentration to be greater than 2 g.m $\mathrm{m}^{-3}$ during the aerobic phase in an AAS process. They also claimed that such high aeration rates are necessary to limit filamentous bacteria growth.

Based on these works, supplementary constraints are added to the MOO problem in order to restrict the solutions space to physically relevant operating conditions: during each cycle, the mean DO should be lower than 0.1 g.m ${ }^{-3}$ which represents anoxic conditions, or higher than 1 or 2 g.m ${ }^{-3}$ (both limits were investigated) which corresponds to aerobic conditions. The MOO problems were solved again using these additional constraints. However, for computational expenses reasons, 4 h cycle lengths are used in problems 1 and 2 instead of $2 \mathrm{~h}$ as previously. In fact, the new problem formulation results in 12 additional constraints (2 DO constraints relative to each cycle), which dramatically increases the computational time: the calculated PFs required about 
21 days of CPU time (problem 3 necessitated about 6 days of computation). Indeed, as the feasible solution space is reduced, the genetic algorithm required more trials before it could generate a child solution with superior performance than its parents (Benyahia, 2009).

Figure 3 shows the effect of the number of cycles per day on the optimal solutions (sludge valorization is taken into consideration in both cases). This time, thanks to the more pertinent problem formulation, the benefit of using time-varying DVs is clearly demonstrated: using a constant aeration rate does not allow achieving lower nitrogen discharge than 35 g.m ${ }^{-3}$. However, Figure 3 reveals an artefact of the model: using time-independent DVs leads to inferior operating costs than the time-varying DVs case, which is obviously aberrant. This artefact is due to the fact that, in the constant DVs case, the mean DO constraints are assessed over 1 day, while in the time-varying DVs case, they apply at each time interval, which leads to stricter restrictions on the admissible solutions.

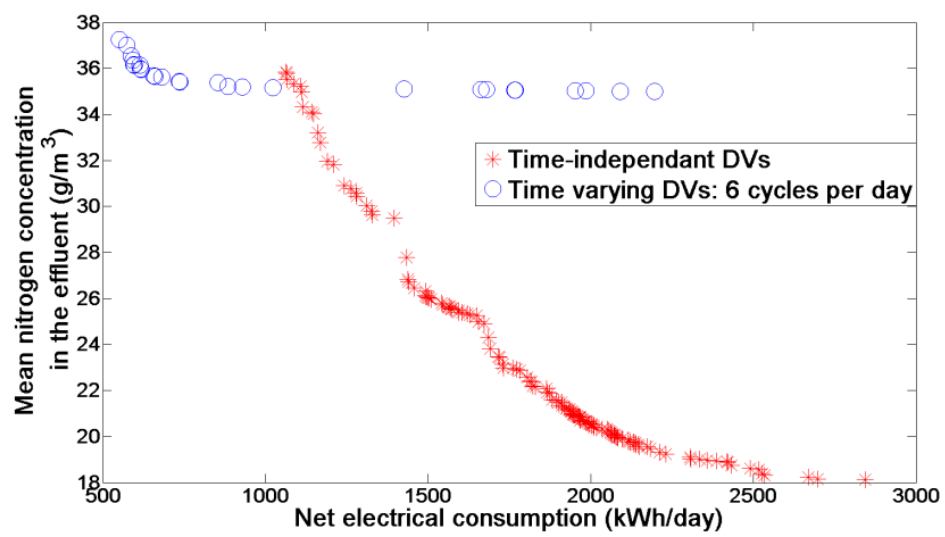

Figure 3: Effect of the number of cycles per day on the Pareto front (the mean DO is constrained to be higher than 2 g. $\mathrm{m}^{-3}$ during the aerobic phase; sludge disposal and valorization are accounted for).

Figure 4 compares the PFs obtained in the situation where no DO constraints are applied (PF already shown in Figure 2), and in the cases where the mean DO concentrations during the aerobic phases are restricted to be above 1 and 2 g.m $\mathrm{m}^{-3}$ (the time intervals length is of $4 \mathrm{~h}$ as already stated). Using DO constraints results in higher exploitation costs and the lowest nitrogen concentration in the effluent that can be achieved increases to about 16.9 g. $\mathrm{m}^{-3}$. However, these results are more realistic and reliable given that the optimal solutions are maintained within the limits of validity of the mathematical model.

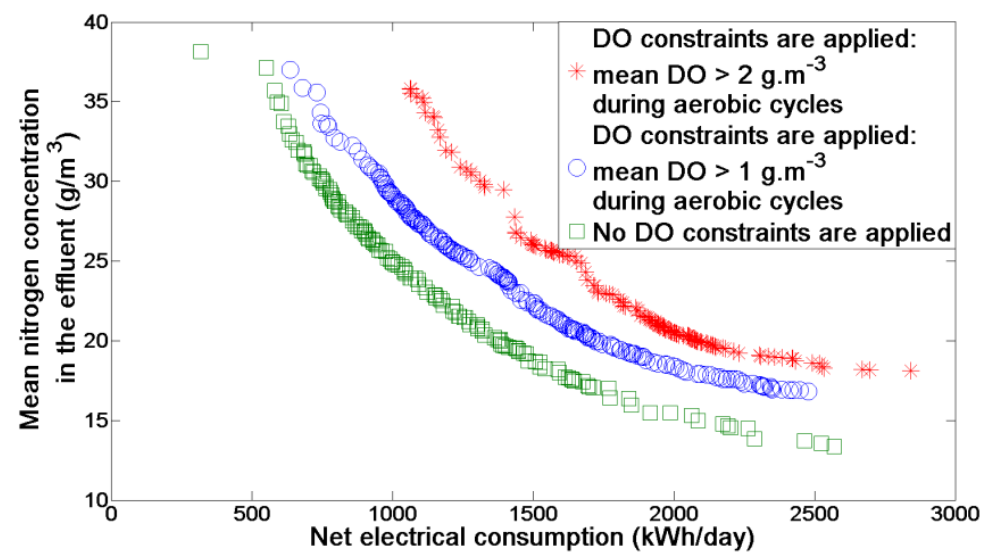

Figure 4: Effect of the DO-related constraints on the Pareto front (sludge disposal and valorization are accounted for).

The optimal solutions achieving high nitrogen removal efficiencies correspond to the operating procedure of an AAS process: aeration is alternated so as to provide cycling anoxic and aerobic conditions. Indeed, the twostep nitrification-denitrification process constitutes the most economical nitrogen abatement strategy. On the other hand, when high nitrogen discharges are tolerated, the optimal solutions deviate from the AAS process functioning since the optimizer favours non-aerated cycles in order to reduce the exploitation costs.

The computed PFs provide a clear picture about the trade-offs between the treatment's quality and exploitation cost. Such data help engineers to decide which operating strategy better balances these competing objectives. 


\subsection{Effect of sludge disposal and valorization}

Figure 5 shows the PFs for the cases where sludge disposal and valorization are respectively accounted and not accounted for in the exploitation costs objective function (DO constraints are used in both problems; DO $>2$ g. $\mathrm{m}^{-3}$ during aerobic cycles). Sludge incineration is shown to be quite profitable energetically, especially when a high nitrogen discharge is tolerated. However, this sludge valorization option is far from allowing attaining the plant's electrical autonomy (although the influent pumping charges are not even considered in the objective function).

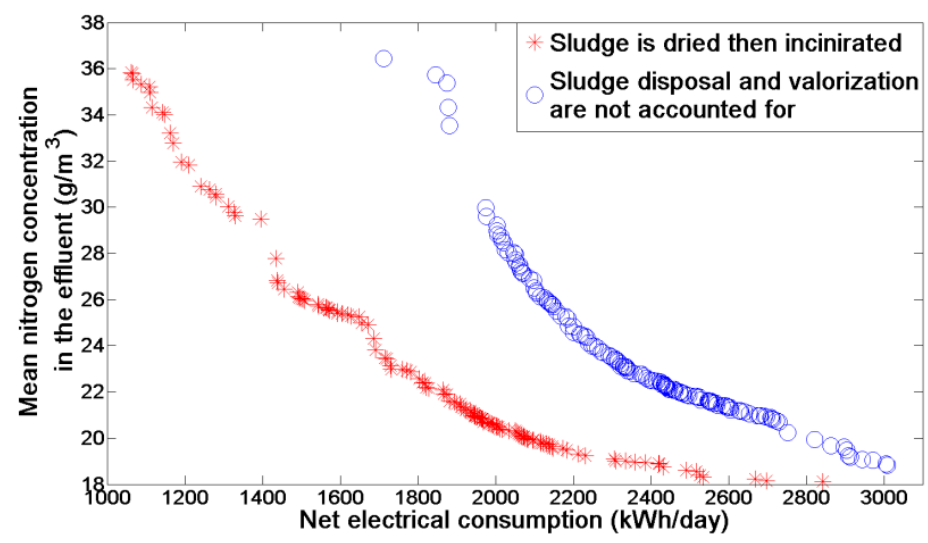

Figure 5: Effect of sludge disposal and valorization on the Pareto front (the mean DO is constrained to be higher than 2 g.m $\mathrm{m}^{-3}$ during the aerobic phase).

This result is somehow in contradiction with the conclusions of Descoins et al. (2012) who found that, unless the discharge limits are very tight, the anaerobic digestion of the sludge allows the WWTP to be electrically autonomous and to produce even important surplus of electricity. It is certainly not possible to directly compare the outcomes of the two studies since the considered plant layouts, the used cost functions, the influent characteristics and the sludge valorization scenarios are different. Nonetheless, we believe that our results are more reliable: indeed, a time-varying influent is used (while Descoins et al. (2012) have considered a steady influent), several constraints (of which DO constraints) ensuring physically relevant results are imposed and various crucial phenomena are accounted for in the model (as the reduction of the mass transfer efficiency, see Section 3.3). On the other hand, it should be noted that Descoins et al. (2012) have considered the anaerobic digestion of both primary and secondary sludge what may partly sustain their outcomes (especially that digestion is generally more profitable than incineration).

\subsection{Effect of the reduction of the oxygen transfer rate}

As already mentioned, to the authors' knowledge, accounting for the reduction of the oxygenation efficiency (Equation 9) is novel in the framework of the optimization of ASPs' operation/design. To assess the importance of the phenomenon, the MOO problem is solved again assuming a constant $\alpha$ equal to unity. As shown in Figure 6 , neglecting this effect leads to a significant underestimation of the exploitation costs. 


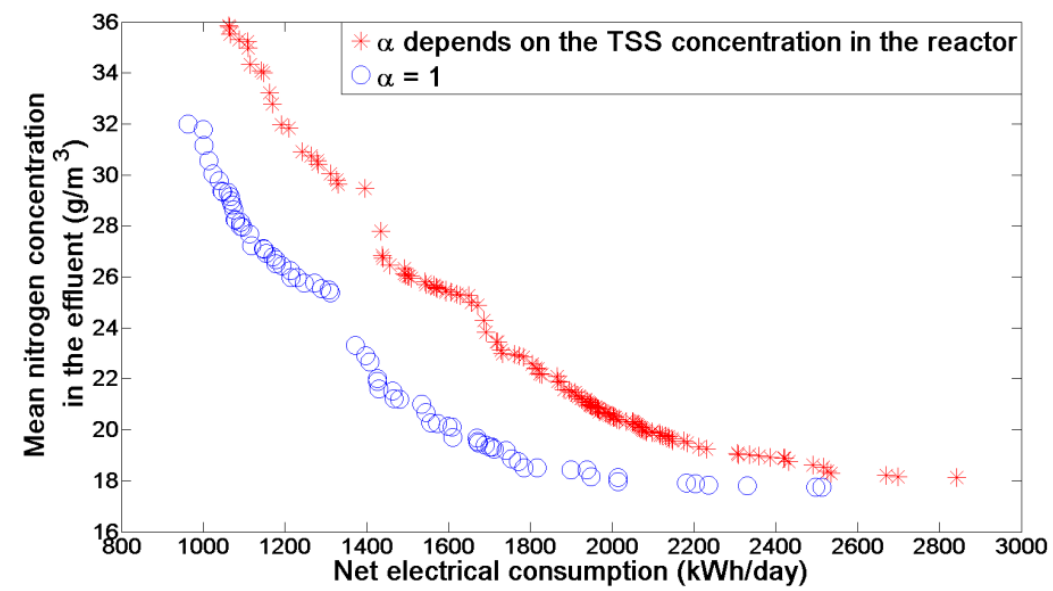

Figure 6: Effect of the reduction of the oxygen transfer rate on the Pareto front (the mean DO is constrained to be higher than 2 g.m ${ }^{-3}$ during the aerobic phase).

Finally, this result emphasizes the need of an accurate modeling of the occurring phenomena and a correct formulation of the optimization problem. In our opinion, several issues deserve careful attention in future works, among which: additional constraints preventing anaerobic conditions (unless a suitable model is used), accounting for the effect of the operating conditions on the sludge settleability and estimating the sludge calorific value based on its composition.

\section{Conclusion}

This paper addressed a multi-objective optimal control of a small-size wastewater treatment plant where the excess sludge produced is incinerated for electricity production. Two objective functions to minimize were considered, the process operating costs and the nitrogen discharge, while the concentrations of carbonaceous matter in the effluent were dealt with through inequality constraints.

A rigorous formulation of the optimization problem was proposed in order to obtain reliable and physically relevant solutions. Thus, the effluent constraints were applied only after a large time delay so that the computed solutions do not depend on the arbitrarily guessed initial conditions whose effects should vanish with time. The modeling of some physical phenomena was improved, for example, the reduction of the oxygen transfer rate depending on the suspended solids concentration in the mixed liquor was accounted for in the model. The sludge age was restricted between 4 and 30 days to guarantee good floc settleability and to limit the sludge mineralization. The mean dissolved oxygen concentration in the reactor was constrained to be lower than 0.1 g.m $\mathrm{m}^{-3}$ or higher than $1 \mathrm{~g} . \mathrm{m}^{-3}$. In fact, contrary to what is observed in practice, in the framework of ASM1, intermediate dissolved oxygen values allow an excellent treatment with low operating charges.

The computed Pareto fronts illustrated the trade-offs between the treatment efficiency and the operating costs. Sludge incineration revealed to be quite profitable energetically, especially when a high nitrogen discharge is tolerated. However, this sludge valorization scenario does not allow attaining the plant electrical autonomy.

\section{Acknowledgments}

The authors want to thank the CARNOT Institutes of Nancy (ICEEL - Lorraine University) and Marseille (STAR - Aix-Marseille University) for the funding of the project oWWTP.

\section{References}

Alasino N., Mussati M.C., Scenna N., 2007. Wastewater treatment plant synthesis and design. Ind. Eng. Chem. Res. 45, 7497-7512.

Alasino N., Mussati M.C., Scenna N.J., Aguirre P., 2010. Wastewater treatment plant synthesis and design: combined biological nitrogen and phosphorus removal. Ind. Eng. Chem. Res. 49, 8601-8612.

Alex J., Benedetti L., Copp J.B., Gernaey K.V., Jeppsson U., Nopens I., Pons M.N., Rieger L., Rosen C., Steyer J.P., Vanrolleghem P., Winkler S., 2008. Benchmark Simulation Model no.1 (BSM1). IWA Taskgroup on Benchmarking of Control Stategies for WWTPs, Technical Report.

Balku S., Berber R., 2006. Dynamics of an activated sludge process with nitrification and denitrification: Start-up simulation and optimization using evolutionary algorithm. Comput. Chem. Eng. 30, 490-499.

Benyahia B., 2009. Modélisation, expérimentation et optimisation multicritère d'un procédé de copolymérisation en émulsion en présence d'un agent de transfert de chaîne. PhD dissertation, Institut National Polytechnique de Lorraine, France. 
Benyahia B., Latifi M.A., Fonteix C., Pla F., 2011. Multicriteria dynamic optimization of an emulsion copolymerization reactor. Comput. Chem. Eng. 35 (12), 2886-2895.

Chachuat B., Roche N., Latifi M.A., 2005a. Long-term optimal aeration strategies for small-size alternating activated sludge treatment plants. Chem. Eng. Process. 44, 593-606.

Chachuat B., Roche N., Latifi M.A., 2005b. Optimal aeration control of industrial alternating activated sludge plants. Biochem. Eng. J. 23, 277-289.

Chachuat B., Roche N., Latifi M.A., 2001. Dynamic optimisation of small size wastewater treatment plants including nitrification and denitrification processes. Comput.Chem. Eng. 25, 585-593.

Coelho M.A.Z., Russo C., Araújo O.Q.F., 2000. Optimization of a sequencing batch reactor for biological nitrogen removal. Water Res. 34, 2809-2817.

Copp J.B., 2002. The COST simulation benchmark. Description and simulator manual. ISBN 92-894-1658-0, Office for Official Publications of the European Communities, Luxembourg.

Costa L., Espírito-Santo I.A.C.P., Fernandes E.M.G.P., Denysiuk R., 2011. Using a genetic algorithm to solve a bi-objective WWTP process optimization. Oper. Res. Proc., 359-364.

Descoins N., Deleris S., Lestienne R., Trouvé E., Maréchal F., 2012. Energy efficiency in waste water treatments plants: Optimization of activated sludge process coupled with anaerobic digestion. Energy 41, 153-164.

Egea J.A., Gracia I., 2012. Dynamic multiobjective global optimization of a waste water treatment plant for nitrogen removal. $7^{\text {th }}$ Vienna Int. Conf. on Math. Model., 374-379.

El-Shorbaghy W., Arwani A., Droste R.L., 2011. Optimal sizing of activated sludge process with ASM3. Int. J. Civ. Environ. Eng. 11 , $19-55$.

Espírito-Santo I.A.C.P., Fernandes E.M.G.P., Araújo M.M, Ferreira E.C, 2007. Wasted Sludge Treatment Contributions in the WWTP Total Cost. WSEAS Trans. Inf. Sci. Appl. 4, 655-662.

Espírito-Santo I.A.C.P., Fernandes E.M.G.P., Araújo M.M, Ferreira E.C, 2006. How wastewater processes can be optimized using LOQO. Lect. Notes Econ. Math. Syst. 563, 435-455.

Fikar M., Chachuat B., Latifi M.A., 2005. Optimal operation of alternating activated sludge processes. Control Eng. Pract. 13, 853-861.

Gillot S., Héduit A., 2004. Prédiction des capacités d'oxygénation en eau claire des systèmes d'insufflation d'air. Technical report FNDAE 31.

Gillot S., De Clercq B., Defour D., Simoens F., Gernaey K., Vanrolleghem P. A., 1999. Optimization of wastewater treatment plant design and operation using simulation and cost analysis. Proceedings $72^{\text {nd }}$ Annual WEF Conference and Exposition. New Orleans, USA.

Grady Jr. C.P.L., Daigger G.T., Lim H.C., 1999. Biological wastewater treatment. Marcel Dekker, Inc., New York, U.S.A.

Guerrero J., Guisasola A., Vilanova R., Baeza J.A., 2011. Improving the performance of a WWTP control system by model-based setpoint optimisation. Environ. Model. Softw. 26, 492-497.

Guerrero J., Guisasola A., Comas J., Rodrígez-Roda I., Baeza J.A., 2012. Multi-criteria selection of optimum WWTP control setpoints based on microbiology-related failures, effluent quality and operating costs. Chem. Eng. J. 188, 23-29.

Hakanen J., Sahlstedt K., Miettinen K., 2013. Wastewater treatment plant design and operation under multiple conflicting objective functions. Environ. Model. Softw. 46, 240-249.

Hakanen J., Sahlstedt K., Miettinen K., 2011. Wastewater treatment: New insight provided by interactive multiobjective optimization. Decis. Support. Syst. 51, 328-337.

Henze M., Grady C.P., Gujer W., Marais G., Matsuo T., 1987. Activated Sludge Model No. 1. Technical Report 1, IAWQ, London.

Hreiz R., Roche N., Latifi M.A., 2015. Optimal design and operation of activated sludge processes: state-of-the-art. Submitted to the Chemical Engineering Journal.

Kim H., McAvoy T.J., Anderson J.S., Hao O.J., 2000. Control of an alternating aerobic-anoxic activated sludge system- Part 2: optimization using a linearized model. Control Eng. Pract. 8, 279-289.

Marrot B., Barrios-Martinez A., Moulin P., Roche N., 2005.Experimental study of mass transfer phenomena in a cross-flow membrane bioreactor: aeration and membrane separation. Eng. Life Sci. 5, 409-414.

Painmanakul P., Hébrard G., 2008. Effect of different contaminants on the $\alpha$-factor: Local experimental method and modeling. Chem. Eng. Res. Design 86, 1207-1215.

Rigopoulos S., Linke P., 2002. Systematic development of optimal activated sludge process designs. Comput. Chem. Eng. 26, $585-597$.

Rivas A., Irizar I., Ayesa E., 2008. Model-based optimisation of wastewater treatment plants design. Environ. Model. Softw. 23, $435-450$.

Seyssiecq I., Ferrasse J.-H., Roche N., 2003. State-of-the-art: rheological characterization of wastewater treatment sludge. Biochem. Eng. J. $16,41-56$.

Souza S.M., Araújo O.Q.F., Coelho M.A.Z., 2008. Model-based optimization of a sequencing batch reactor for biological nitrogen removal. Bioresour. Technol. 99, 3213-3223.

Takács I., Patry G.G., Nolasco D., 1991. A dynamic model of the clarification-thickening process. Water Res. 25, $1263-1271$.

\section{List of figures}

- $\quad$ Figure 1: Schematic diagram of the basic activated sludge process.

- $\quad$ Figure 2: Pareto fronts when sludge disposal and valorization are respectively accounted and not accounted for in the exploitation costs objective function.

- $\quad$ Figure 3: Effect of the number of cycles per day on the Pareto front (the mean DO is constrained to be higher than 2 g.m ${ }^{-3}$ during the aerobic phase; sludge disposal and valorization are accounted for).

- $\quad$ Figure 4: Effect of the DO-related constraints on the Pareto front (sludge disposal and valorization are accounted for).

- $\quad$ Figure 5: Effect of sludge disposal and valorization on the Pareto front (the mean DO is constrained to be higher than 2 g.m ${ }^{-3}$ during the aerobic phase).

- Figure 6: Effect of the reduction of the oxygen transfer rate on the Pareto front (the mean DO is constrained to be higher than 2 g.m $\mathrm{m}^{-3}$ during the aerobic phase). 